\title{
Additive Manufacturing and Maritime Spare Parts: Benefits and Obstacles for the End-Users
}

\author{
Evanthia Kostidi *, Nikitas Nikitakos and Iosif Progoulakis \\ Department of Shipping Trade and Transport, University of the Aegean, Korai 2a, GR82132 Chios, Greece; \\ nnik@aegean.gr (N.N.); iprogoulakis@aegean.gr (I.P.) \\ * Correspondence: e.kostidi@aegean.gr
}

check for updates

Citation: Kostidi, E.; Nikitakos, N.; Progoulakis, I. Additive

Manufacturing and Maritime Spare Parts: Benefits and Obstacles for the End-Users. J. Mar. Sci. Eng. 2021, 9, 895. https://doi.org/10.3390/ jmse 9080895

Academic Editor: Claudio Ferrari

Received: 13 July 2021

Accepted: 13 August 2021

Published: 19 August 2021

Publisher's Note: MDPI stays neutral with regard to jurisdictional claims in published maps and institutional affiliations.

Copyright: (c) 2021 by the authors. Licensee MDPI, Basel, Switzerland. This article is an open access article distributed under the terms and conditions of the Creative Commons Attribution (CC BY) license (https:// creativecommons.org/licenses/by/ $4.0 /)$.

\begin{abstract}
D printing or additive manufacturing (AM) (in the industrial context) is an innovative, as opposed to subtractive, technology, bringing new opportunities and benefits to the spare part supply chain (SPSC). The aim of this work is to capture the views of the stakeholders at the end of the chain, extruding factors that will benefit the end-user and the factors that are likely to be an obstacle, by employing the questionnaire method. Company objectives regarding spares (cost reductions, improvement of services, space reduction) have been prioritized differently by the stakeholders. The most important barriers according to the participants are the quality assurance of the spare parts made by the new technology followed by the know-how and skills of staff. Other views such as suitable parts are suggested. The practical value of this work, in addition to assessing the readiness of the industry, is that it provides guidance for the successful implementation of AM in the maritime industry.
\end{abstract}

Keywords: 3D printing; additive manufacturing; spare part supply chain; maritime

\section{Introduction}

Machinery (in general) is subject to gradual deterioration that makes preventive or corrective maintenance a necessity, thus requiring the availability of spare parts. The maritime industry is characterized by the heavy utilization of equipment and machinery under harsh and corrosive operating conditions and that makes the requirements of maintenance particularly critical due to the detrimental financial and safety consequences of downtime. The availability of parts at the point of consumption makes inventory necessary for suppliers to respond quickly to demand. Keeping an inventory of spare parts causes a financial burden to maritime companies and parts suppliers, mainly in capital cost expenditure as well as logistical storage. Spare parts supply chain (SPSC) plays an important role in keeping the maritime assets operating efficiently and safely. Maintenance networks involve many actors such as the owners of the assets, system integrators, original equipment manufacturers $(\mathrm{OEM})$ and the service providers and their logistics service providers [1].

3D printing or additive manufacturing (AM) ( $\mathrm{n}$ the industrial context) (The terms "additive manufacturing" and "3D printing" are used interchangeably in the literature although there are distinct differences as defined in ISO/ASTM 52900(en) [2]. Additive manufacturing is used in the industrial context but $3 \mathrm{D}$ printing is the more commonly known term as it is used in popular media. This is why the term "3D printing" was used in the communication with the stakeholders.) is an innovative, as opposed to subtractive, technology, bringing new opportunities and benefits to the spare parts supply chain because it enables distributed manufacturing in small batches, thus minimizing the inventory and reducing delays and costs. It is based on the principle of the construction in layers by directly converting the 3D data into physical objects [3]. As AM provides the ability to manufacture finished components in a decentralized manner, many researchers argue in favor of digitizing spare parts and their decentralized construction [4,5]. With the possibility of end-use components being created with AM, several researchers have proposed that spare 
parts could be digitized and additively manufactured [4-6]. Maritime is not to be omitted from technological developments. Top global marine propulsion engine vendors motivated by the benefits of AM have introduced this new technology not only in prototyping but also in their production process. Initiatives such as the "Pilot Project 3D printing of Marine Spares" [7], "Green Ship of the Future" [8] and "Maritime and Port Authority of Singapore" [9] aim to explore the practical use of AM. Academic research aims to explore new materials and production methods for the maritime environment. The use of innovative manufacturing routes is based on the use of innovative materials such as the application of fiber-reinforced composite materials in the marine environment; the latest advances in this area are presented by Rubino et al. [10]. The article by Parmar et al. depicts the present and future scenarios related to the application of Industry 4.0 concepts to polymer composite (fiber-reinforced) manufacturing and the recent and potential developments in robotic and additive manufacturing [11]. The shipping industry has already entered the era of digitalization and an optimized flow of information by integrating different stakeholders, people at sea as well as technology applications and processes should be viewed as a very crucial strategic asset for any modern shipping company [12]. Salmi et al. [6] investigated the impact of digital spare parts on operating models using five general supply chain models ranging from fully concentrated to fully distributed.

The impacts of AM technologies are not partial or isolated disruptions but rather encompass a range of changes whose overall consequences spread across different phases of the supply chain [13]. To determine how AM could benefit the supply chain, executives should examine all the levels from the product design (product functional requirement and design parameters) to the manufacturing lines as well as the location and layout of the physical facilities [14].

The spare parts supply chain with the introduction of AM has attracted the interest of a number of researchers. Most of the studies cover the following industries: aerospace/aviation [15-19], marine and offshore [16,20], automotive [21,22], mechanical engineering [17] and medical $[17,23]$. The reason for the interest in this particular supply chain is that spare parts differ from consumer products in terms of demand (i.e., sporadic and difficult to predict) [24-26] and in many cases there are relatively limited historical demand data available [27]. Transporting means operating away from their base and, in many cases, in random paths, presenting additional difficulties in being supplied with the necessary spare parts for their operability. The shipping cost in several cases (i.e., isolated or difficult to reach areas) may be higher than the part itself in addition to the downtime cost.

Despite its importance in worldwide trade, the maritime industry did not evolve in regard to the SPSC in comparison with other industries, mainly because of its smaller footprint. For this reason, for the application of any lessons learned from other industries, the specific characteristics of the maritime domain should be taken into account. For example, the vessel is in an isolated environment, the environment is highly corrosive, extreme and frequent turbulence and vibrations are present, vessels (as well as land offices) are staffed by technicians and information systems have been long applied [28].

Although, as mentioned above, there are several studies on the implementation of AM technology in areas similar to the maritime industry (with moving assets or isolated environments), studies specifically on the maritime industry are scarce. The aim of this work is to expose the factors that may push the digitization process in the spare part supply chain with the introduction of AM and the factors that are likely to be an obstacle to it. The use of the technology in question or similar previous technologies, technological infrastructures and technology awareness are an indication for seedbed ground. This work captures the views and expectations of the stakeholders in the lower end of the SPSC (endusers) in the maritime industry and to the best of our knowledge no similar work has been done before. The rest of the paper is structured as follows: first, the methodology used is presented. The literature review then follows in order to formulate the questionnaire. Next, the collected views of the involved stakeholders at the end of the SPSC (end-users) are 
analyzed and the results are presented. Finally, the results are discussed and conclusions are drawn.

\section{Methodology}

As our research aimed to explore the potential of introducing AM in the spare parts supply chain in the maritime industry, the questionnaire method was selected for capturing the perceptions of the involved stakeholders in order to get an understanding of motives and fears. The selected target group interviewees were at the end of the SPSC: people onboard a vessel (bridge and engine crew) and in a land office (ship owners or chief executive officers; staff in technical, procurement, training, research and development departments). Most of them had no or limited AM knowledge, so a short presentation of the basics of AM took place. The shipping companies visited for interviews were not restricted to a particular type of vessel. The term "3D printing" was used instead of the term "Additive Manufacturing" throughout the interviews because it was more understandable by survey participants due to its use in the media.

A literature review was carried out in order to formulate the questionnaire, mainly by searching in Google Scholar for the terms "Additive Manufacturing and the spare part supply chain", "benefits and Additive Manufacturing" and "barriers/challenges and Additive Manufacturing". In order to formulate the questions, preliminary meetings were arranged with representative people of all the mentioned groups. During these meetings, the available technology, its capability and the benefits to the SPSC were presented. The skepticism of meeting participants was captured in order to record the challenges that such a change would face. The preliminary meetings gave us an idea how to structure the questionnaire. In order to get as many as possible views, two well-known marine exhibitions were selected because they attracted all the targeted stakeholders. The views of academics were recorded at relevant scientific conferences.

The interview participants were asked to rank the objectives of the company (regarding spares) such as cost reductions, improved service, storage space reduction or any other company values that would be enhanced with the introduction of the proposed technology. All changes (including technological ones) encounter obstacles and realizing what barriers are to be expected when a part is made by the use of 3D printing will help for better preparation. The criteria for selecting parts to be made by $3 \mathrm{D}$ printing may differentiate from the criteria met in the literature due to the nature of the maritime industry.

\section{Literature Review in Order to Formulate the Questionnaire}

An extensive literature review was undertaken to identify suitable academic and industry research and standards that could assist in the formulation of the survey questionnaire.

\subsection{Main Positive Effects of Additive Manufacturing and the Spare Part Supply Chain}

The motives to introduce new technology vary considerably by industry. In aerospace, components need to be geometrically optimized to result in lighter structures and thus reduce aircraft weight and fuel consumption. In the automotive industry, an important motive is the rapid creation of prototypes and tools as well as the supply of spare parts for old vehicles. These incentives lead to research in the aerospace and automotive industries to exploit the potential of new technology. As AM matures in shipping, specific incentives will emerge. Meanwhile, as the supply of spare parts is important for vessel maintenance, shipping can learn from studies in other industries. The main positive effects of the application of AM in the SPSC in the area of moving assets stated by authors in the literature are (Table 1) asset availability [19], economic efficiency [17,20], reduced inventory [16,18,29], improved service [15,18,29], lead time reduction [22], better supply chain performance [21] and decreasing carbon emissions $[17,18]$. 
Table 1. Main positive effects of additive manufacturing on the spare part supply chain.

\begin{tabular}{|c|c|c|c|c|c|c|c|c|c|}
\hline \multirow[b]{2}{*}{$\begin{array}{l}\text { Influence on the } \\
\text { Supply Chain }\end{array}$} & \multirow[b]{2}{*}{$\begin{array}{l}\text { Holmström } \\
\text { et al. } \\
\text { (2010) [29] }\end{array}$} & \multicolumn{8}{|c|}{ Author(s) } \\
\hline & & $\begin{array}{l}\text { Khajavi, } \\
\text { et al. } \\
\text { (2014) [15] }\end{array}$ & $\begin{array}{l}\text { Liu, et al., } \\
\text { (2014) [16] }\end{array}$ & $\begin{array}{l}\text { Ratnayake, } \\
\text { (2016) [22] }\end{array}$ & $\begin{array}{l}\text { Li, et al. } \\
\text { (2017) [17] }\end{array}$ & $\begin{array}{l}\text { Ghadge, } \\
\text { et al. } \\
\text { (2018) [18] }\end{array}$ & $\begin{array}{l}\text { Khajavi, } \\
\text { et al. } \\
\text { (2018) [19] }\end{array}$ & $\begin{array}{l}\text { Westerweel, } \\
\text { et al. } \\
\text { (2018) [20] }\end{array}$ & $\begin{array}{c}\text { Delic, } \\
\text { et al. } \\
\text { (2019) [21] }\end{array}$ \\
\hline Asset availability & & & & & & & $\sqrt{ }$ & $\sqrt{ }$ & \\
\hline $\begin{array}{l}\text { Economic } \\
\text { efficiency }\end{array}$ & & & & & $\sqrt{ }$ & & $\sqrt{ }$ & $\sqrt{ }$ & \\
\hline $\begin{array}{l}\text { Reduced } \\
\text { inventory }\end{array}$ & $\sqrt{ }$ & & $\sqrt{ }$ & & & $\sqrt{ }$ & & & \\
\hline Improved service & $\sqrt{ }$ & $\sqrt{ }$ & & & & $\sqrt{ }$ & & & \\
\hline $\begin{array}{l}\text { Lead time } \\
\text { reduction }\end{array}$ & & & & $\sqrt{ }$ & & & & & \\
\hline $\begin{array}{l}\text { Supply chain } \\
\text { performance }\end{array}$ & & & & & & & & & $\sqrt{ }$ \\
\hline Environmental & & & & & $\sqrt{ }$ & $\sqrt{ }$ & & & \\
\hline
\end{tabular}

Company objectives lead company decisions and concentrate efforts in obtaining them. The SPSC in the maritime industry involves many stakeholders whose objectives may differ from each other so any exploration of the potential of additive manufacturing improvements should start with noting the objectives of each stakeholder.

Q1. What are the expected benefits from the introduction of $3 D$ printing as viewed by the stakeholders at the end of the SPSC (end-users)?

\subsection{Barriers toward the Introduction of $A M$}

All changes (including technological ones) encounter obstacles and must be properly mitigated. Vogelsang et al. [30] analyzed the barriers toward the digitalization of enterprises in manufacturing and grouped them into individual, organizational, environmental and technical barriers as well as skills shortage. Barriers such as standardization, quality assurance, intellectual property rights protection, the legacy of non-digitalized products and component information have to be further investigated [31]. Among major technical barriers, a low number of usable materials, insufficient accuracy levels, tolerances and the build chamber size limitation [32] need to be overcome. Another barrier is that the industrial design methodologies applied are for traditional manufacturing and do not take into account the capabilities of AM. CAD (computer-aided design) files often do not exist and technical drawings can be difficult to locate [33].

The need to ensure the functionality and compatibility of products as well as consumer safety are addressed by already published and upcoming standards [34]. Certification and quality assurance are required in order to give confidence to all interested parties that a product, process or service fulfils the specified requirements [35]. Small batch production or the customization of products by AM require new quality assurance (i.e., non-destructive) and certification methods for the production of procedures and the products. This need aims to cover the published guidance notes by classification and certification societies such as Lloyd's Register and TWI (The Welding Institute) [36], DNV (Det Norske Veritas) [37], ABS (American Bureau of Shipping) [38] and the Bureau Veritas Marine and Offshore [39].

Additive manufacturing (AM) is revolutionizing the industrial landscape and these changes require new engineering and management skills to exploit fully and sustainably the benefits offered by these advanced technologies. New technology creates a lack of talent, a need for training in specializations and a workforce adaptable to change [40].

Although there are existing legal [31], cyber security [41], manufacturing time and cost issues, the most frequently met barriers in the literature to produce a part by the use of 3D printing are: 
1. Technology know-how;

2. Staff skills;

3. Quality assurance.

Knowing the expected obstacles when a part is made by the use of 3D printing will help for a better preparation.

Q2. What are the barriers influencing the application of $3 D$ printing, as viewed by the stakeholders at the end of the SPSC?

The established company policy and culture toward the use of a part made in a different way than the usual procedure (genuine spare) may influence the successful introduction of the new technology. OEM, even in cases that obtain parts through subcontractors, control the spare part flow toward the end-user. In a few cases, spare part sales are a considerable source of income for OEM. Constraints such as machinery guarantees may also influence the adaptation of the AM technology.

Q2.1. What is the attitude of each stakeholder toward the use of a part made in a different way than the usual procedure (3D printed)?

\subsection{Characteristics of the Suitable Spare Part}

The characteristics of the suitable spare part as proposed from initiatives in the area of the maritime industry $[7,9]$ can provide a picture of the parts that may have the potential for 3D printing. Parts that are infrequently demanded but must be available in case they are needed, especially those of a high supply risk, must be in the inventory. Parts that are ordered in small quantities usually have quite an expensive overhead cost. Keeping high value parts in the inventory ties up capital. If parts are of a high design complexity, they are difficult to be made otherwise (i.e., in a lathe) or they are made up of many components that require assembly. For practical reasons, the chosen parts must be of such a size that can fit in the process chamber. These are presented in Table 2.

Table 2. Suitable part characteristics for 3D printing for the maritime industry.

\begin{tabular}{c}
\hline Suitable Part Characteristics \\
\hline Small size that can fit in the process chamber \\
Small order quantity \\
Infrequently demanded \\
High value \\
High design complexity \\
High supply risk \\
\hline
\end{tabular}

Not all parts can be made by AM for various reasons. That is why criteria are set in selecting parts for 3D printing. Obviously, an automated process of selection is fast and economic but even in cases where appropriate digital data exist, the human view is valuable. Various methods have been proposed to assist in that process, each one having advantages and disadvantages. The approach by Knofius et al. [42] relies on spare part information that is easily retrievable from the company databases. The trade-off methodology by Lindemann et al. [43] involves AM experts and part owners. Overall, prior methods on part candidacy identification may differ in strategies but mostly show a deficiency in comprehensiveness, efficiency and objectiveness. Therefore, a fast decision support system that requires the least user inputs and minimum AM expertise but computationally produces reliable recommendations of AM eligibility is demanding in the task planning and conceptual stage of the product redesign [44].

Although AM brings benefits to spare part production, it is an expensive way to fabricate components. That is why it is subjected to high value items (that lead to a high inventory cost). The proposed characteristics of the suitable spare part in the literature suggest high value parts. Due to maritime nature, a low-cost item to reach a vessel may 
have a huge transportation cost in addition to the damage or safety from a missing part, thus leading to the high value of the part.

Q3. Do you think 3D printing could be applied for low-cost items (such as an elastic sealing ring)?

Knowledge of the technology in question or similar previous technologies, technological infrastructures and technology awareness were an indication for seedbed ground.

\subsection{Seedbed Ground Elements}

3D printing is becoming a term increasingly known through media reports, which present impressive constructions. They also show the advantages and this makes the decision makers think of applying it to their own needs. Technology awareness, technological infrastructures and the use of the technology in question or similar previous technology was an indication for seedbed ground (Figure 1).

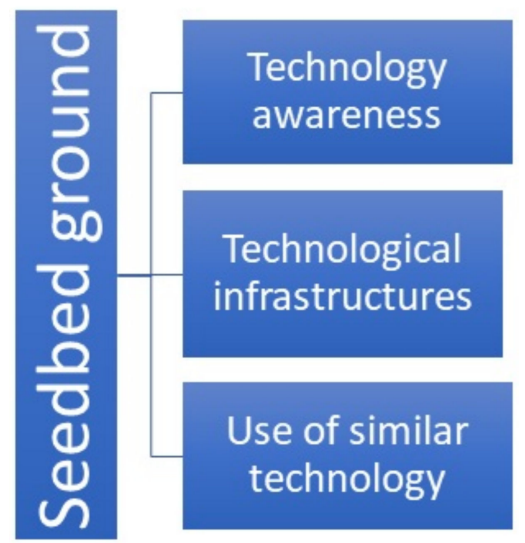

Figure 1. Seedbed ground for the acceptance of new technology.

Q4.1. Is your company thinking of/examining the use of $3 D$ printing?

A computerized manufacturing process such as computerized numerical control $(\mathrm{CNC})$ is based on pre-programmed software and code that control the movement of the production equipment. This technology is similar to that of a 3D printer, which has a complexity and requires advanced skills. A company or a person familiar with a CNC operation could easily move to 3D printing.

Q4.2. Is your company using CNC (computer controlled machine) technology?

Making or refurbishing spare parts on board by the use of a lathe, for example, or another technique depends on the company policy as it requires trained personnel and may involve the risk of failure, accidents or the prohibition of warranty commitments.

Q4.3. Is your company making or refurbishing spare parts on board (i.e., use a lathe or some other technique to make a sealing ring)?

It is well-known that manufacturers secure a portion of their profits (perhaps the largest) from spare parts sales. They require proper maintenance and genuine spare parts from the users of their machines in order to maintain the warranty. For these reasons, but also to protect themselves from imitations, they are protective of the technical information they provide, limiting it to what is absolutely necessary.

Q4.4. What information is available for manufacturing spares?

\section{Research Results Analysis}

The total volume of the survey questionnaires that were collected was 140. The target number was 200 but several, although kind enough to contribute to a free talk, did not fill 
in the questionnaire. The participants were grouped as crew engine, crew bridge, technical, ship owners/CEOs (Chief Executive Officers) and other R\&D (Research \& Development), training, academic]. It should be noted that the majority of survey participants were male $(83 \%)$ as the male population is by far higher than the female population in the maritime industry.

\subsection{Expected Benefits}

\subsubsection{Expected Contribution to Cost Reductions}

The participants ranked how 3D printing would contribute to the company objectives of cost reductions, improving services and storage space reductions. The results are presented in Figure 2.

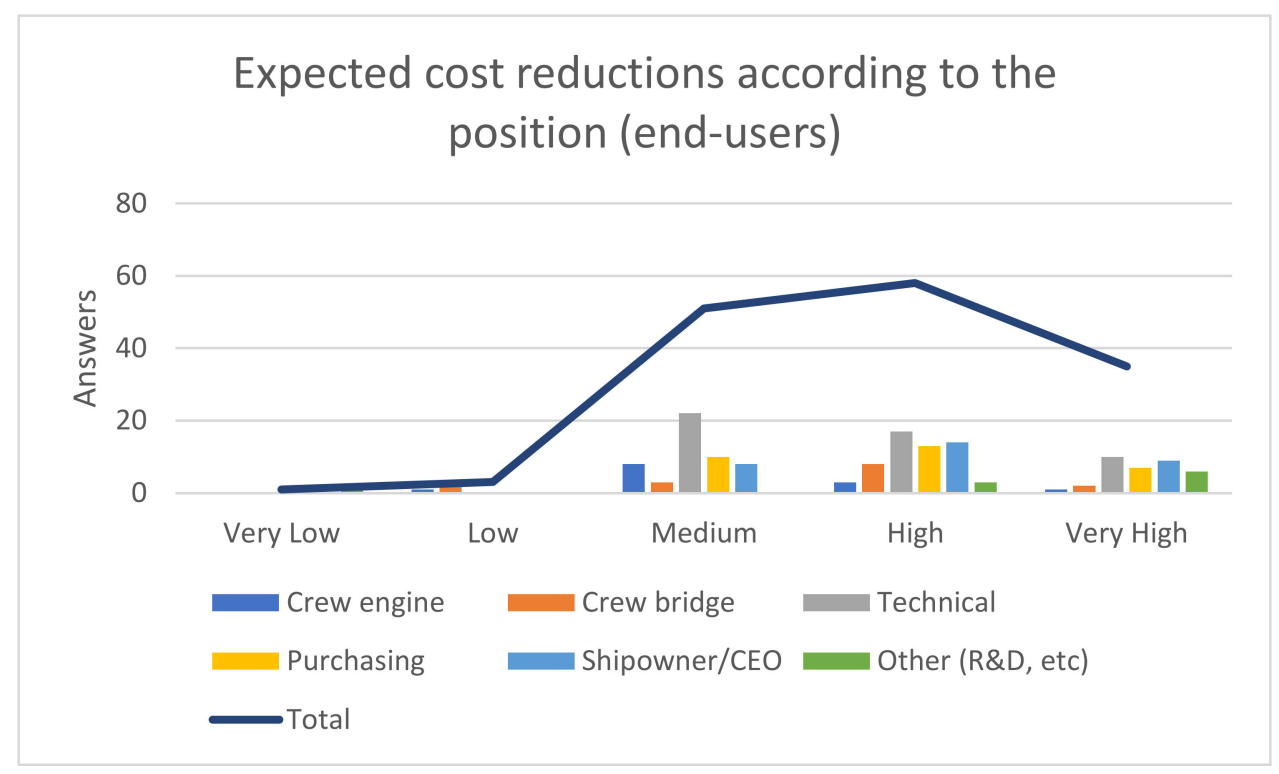

Figure 2. Expected cost reductions according to the position in the company.

Cost reductions seemed to vary as an objective for end-user participants even within their company role. Engine crew as well as technical participants valued cost reductions as of medium importance, with land office technical personnel appearing to be more concerned about cost. This is totally understandable because spare parts should be found when needed despite the cost but the budget must be kept within the set limits. On the other hand, shipowner/CEO participants, bridge crew and purchasing participants were more cautious regarding cost reductions as they preferred to save money.

\subsubsection{Expected Improvement in Services According to the Role in the Company}

Regarding the improvement of services as a whole for end-user participants, these were regarded to be of medium importance. As far as the role of the company for end-user participants, the improvement of services seemed to vary as an objective. This is depicted in Figure 3.

\subsubsection{Expected Storage Space Reduction by the Role in the Company}

As far as the role in the company for end-user participants, storage space reductions seemed to vary as an objective once again. Crew engine, crew bridge and technical participants believed that the storage space reduction objective was of medium importance as they were more concerned about the final parts themselves. The same applied for shipowner/CEO participants as well as purchasing personnel. This is depicted in Figure 4. 


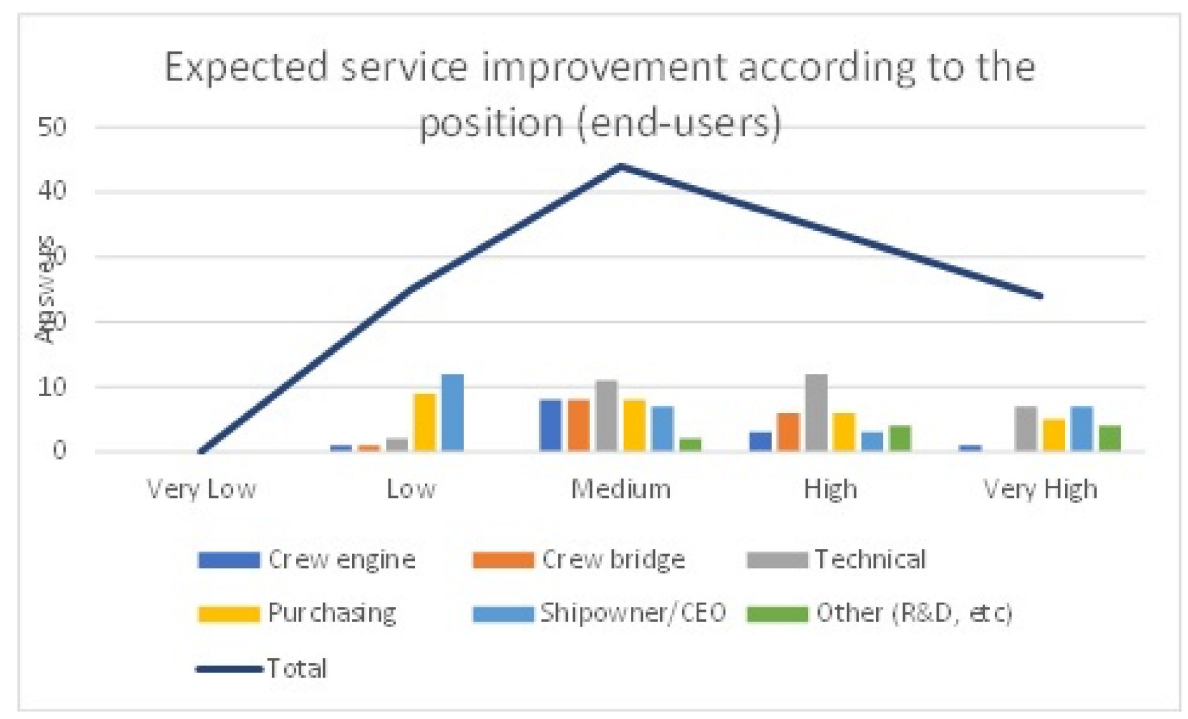

Figure 3. Expected service improvement according to the position.

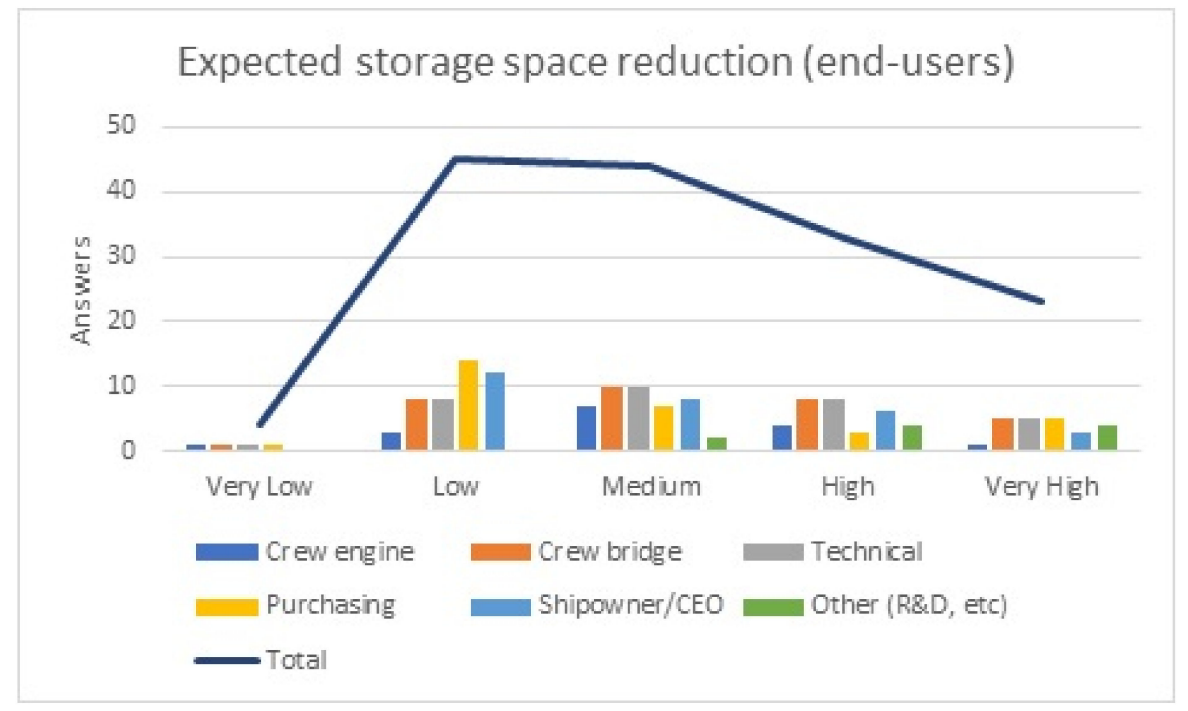

Figure 4. Expected storage space reduction.

Examining the expectations from the participants regardless of the company position, the end-users expected a low to medium space reduction and service improvement and high cost reductions. These are shown in Figure 5.

\subsection{Barriers}

In reference to the barriers of using parts made by 3D printing, end-user participants thought that the most important was the quality assurance of the spare parts made by the new technology. Technology know-how and staff skills followed. The survey results on these barriers are shown in Figure 6.

The importance of quality came to the surface from the answer to the question for the use of a part made in a different way than the usual procedure (3D printed) followed in the industry.

The majority of the participants answered that they would fit a 3D printed part on the equipment only if it had a quality assurance (Figure 7). 


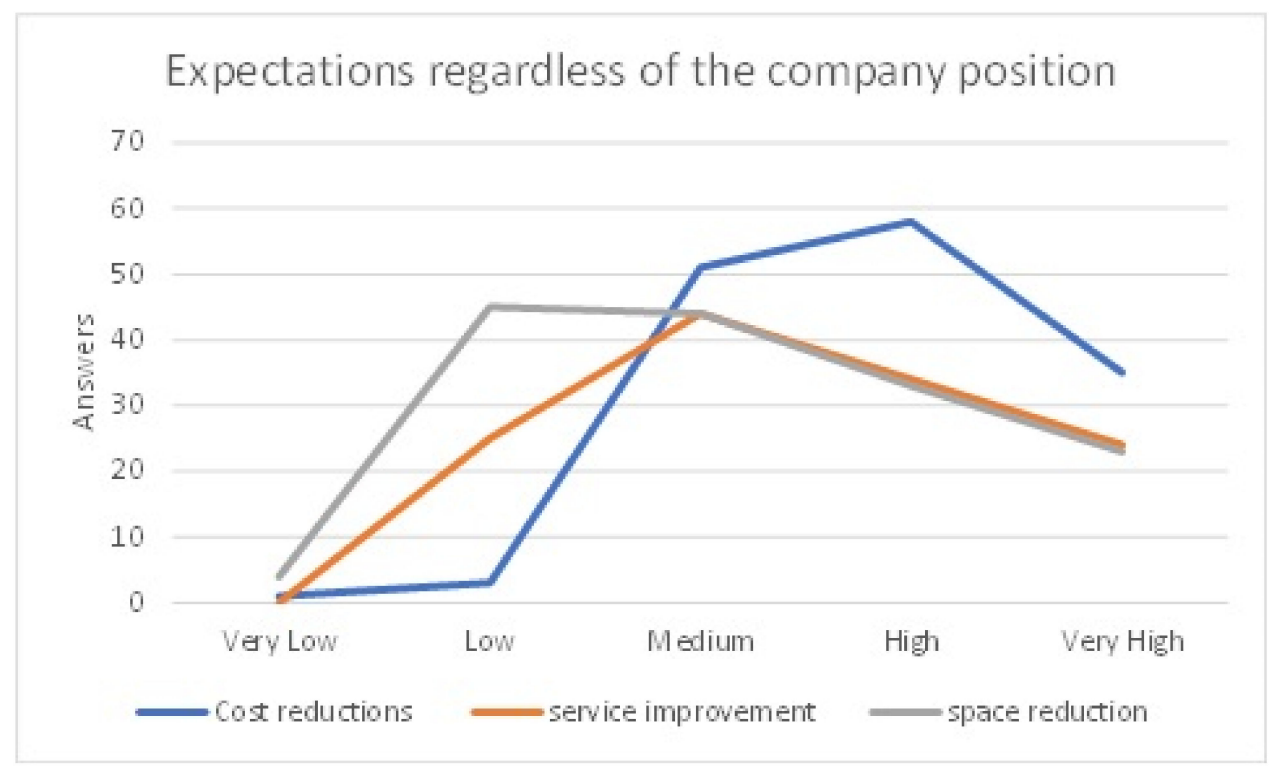

Figure 5. Expectations from the participants regardless of the company position.

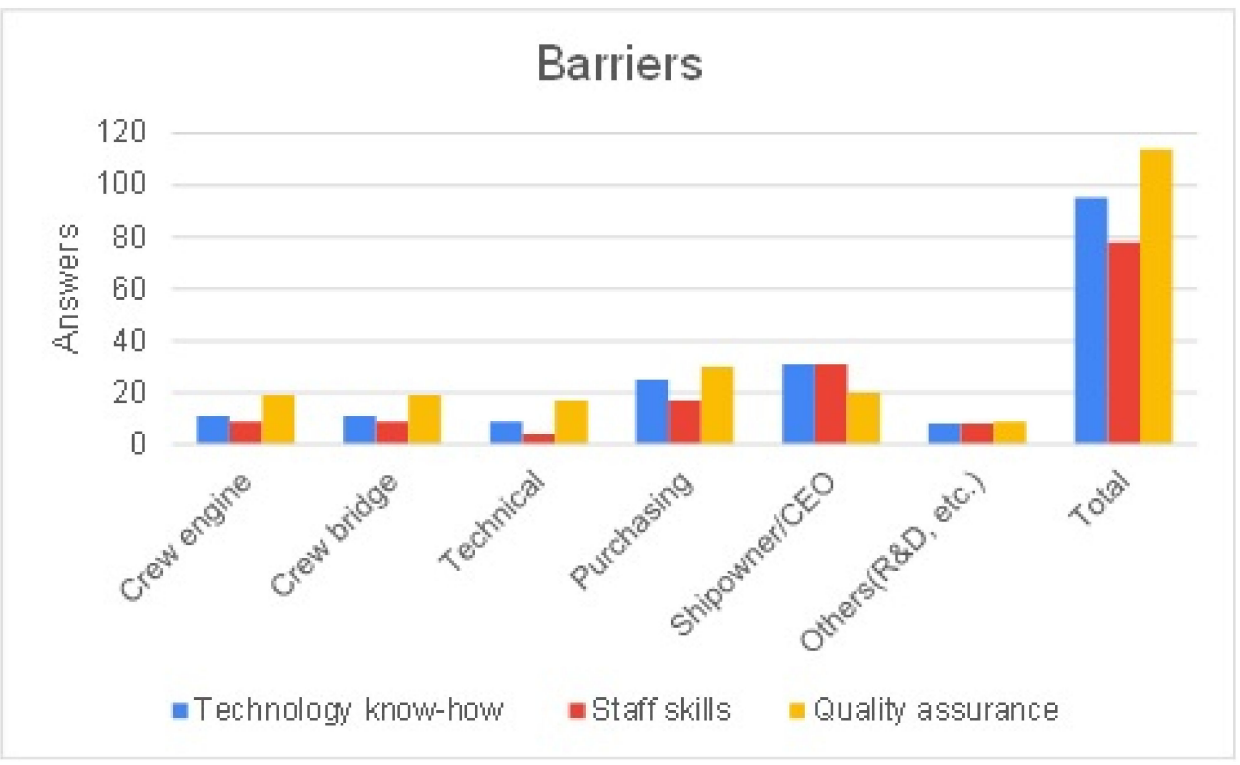

Figure 6. Barriers of using parts made by 3D printing.

\subsection{D Printing for Low-Cost Items}

A great percentage of the survey responders answered that if 3D printing was applied, it would make repairs easier. One could note that all the answers from the land office personnel were positive as they had knowledge of what the cost of a low-value spare could reach if transportation cost was included in addition to the difficulties in finding them (Figure 8). Academics were also positive.

\subsection{Seedbed Ground}

The use or awareness of 3D printing was an indication for seedbed ground. When asked if they examined or thought about the use of 3D printing, most answered that they did not examine nor did they think about it; many had thought about it, others did not know and a few were concerned about it at the moment. Shipowners/CEOs showed a positive attitude and that was regarded to be more than promising as they are mainly responsible for the acceptance of companies that may lead to the adoption of new technology (Figure 9). 


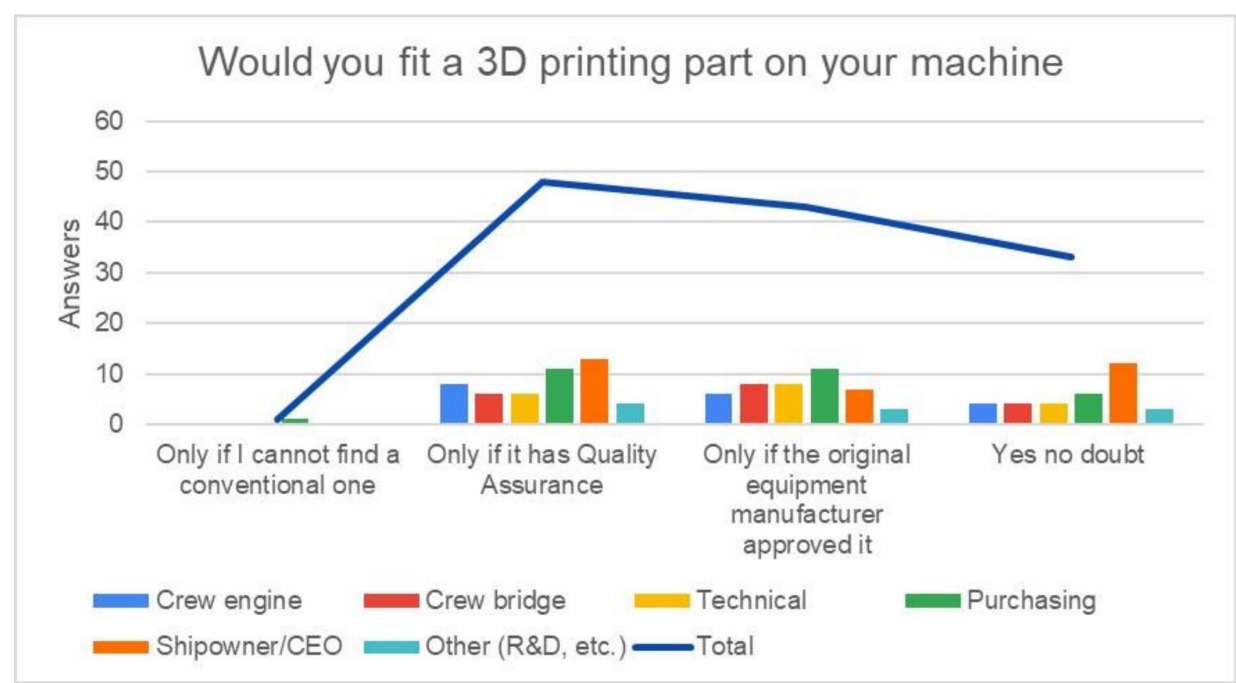

Figure 7. Response to the question "Would you fit a 3D printing part on your machine".

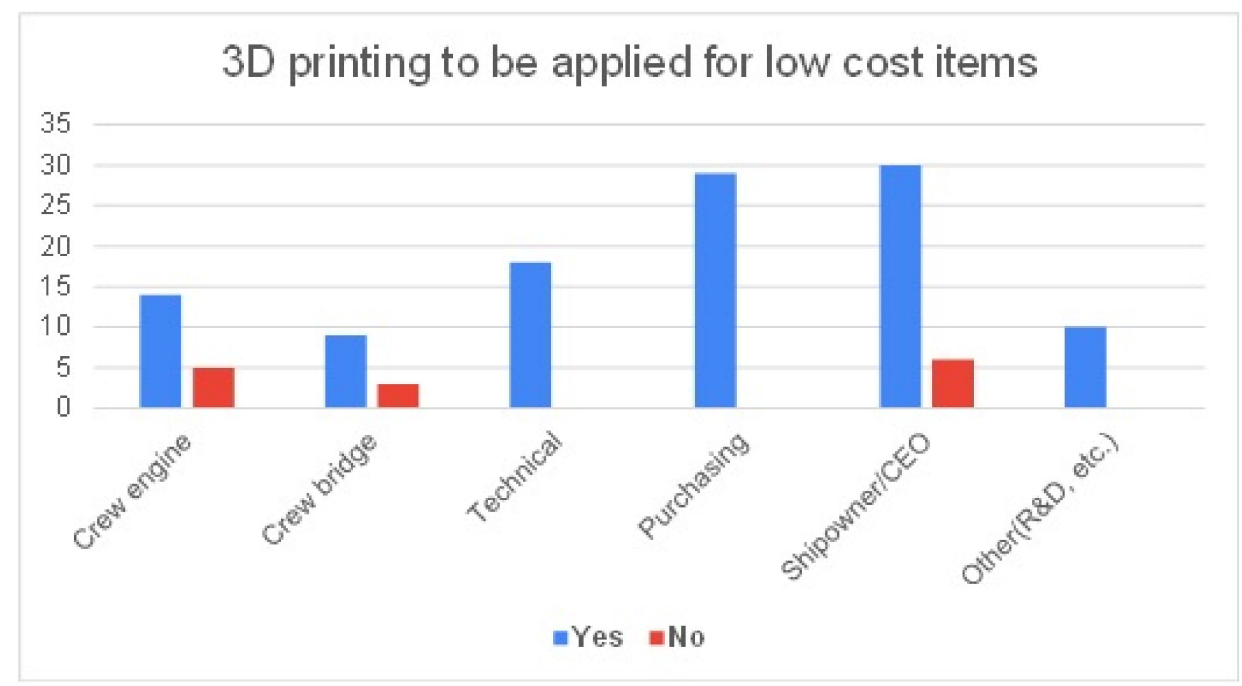

Figure 8. Response to whether 3D printing could be applied for low-cost items.

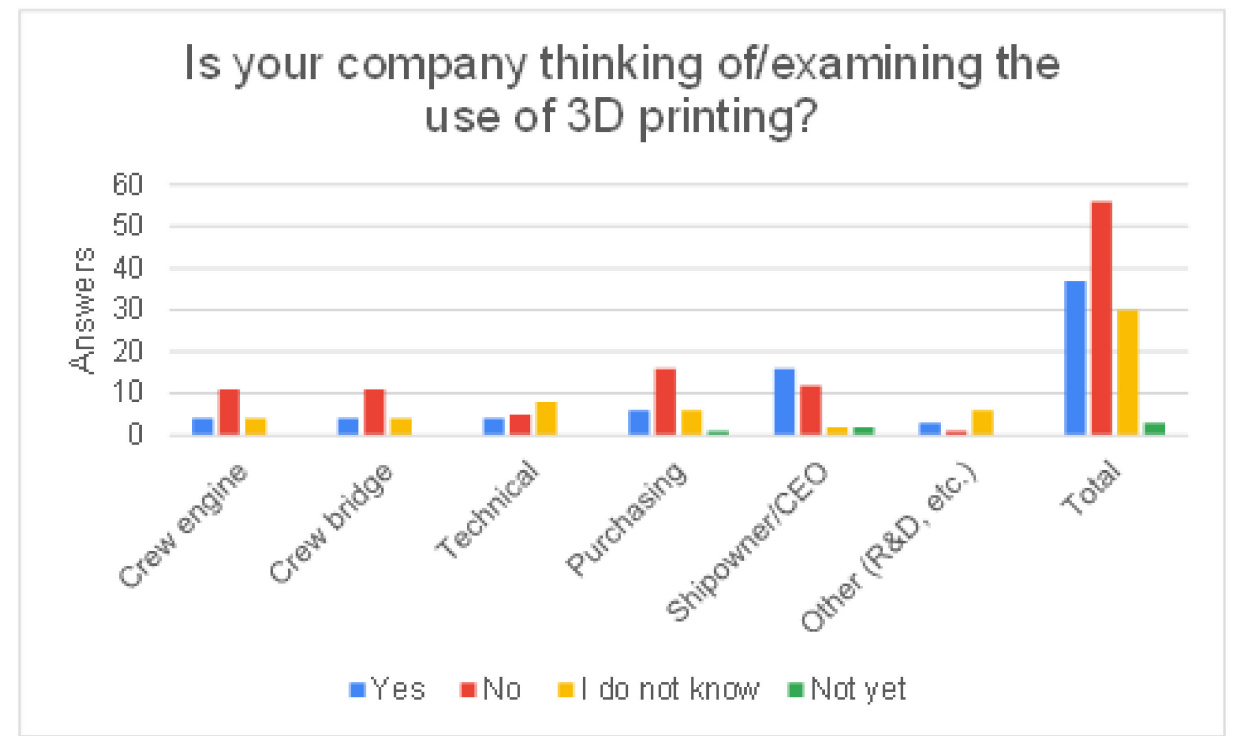

Figure 9. Results for the examination of the use of 3D printing. 
The use of CNC technology that would make the transition to 3D printing easier because of the similarities between the two technologies seemed to be absent from the vessels. The positive answers from the staff of the technical department may be due to making parts on shore in local workshops and needs further study. These results are presented in Figure 10.

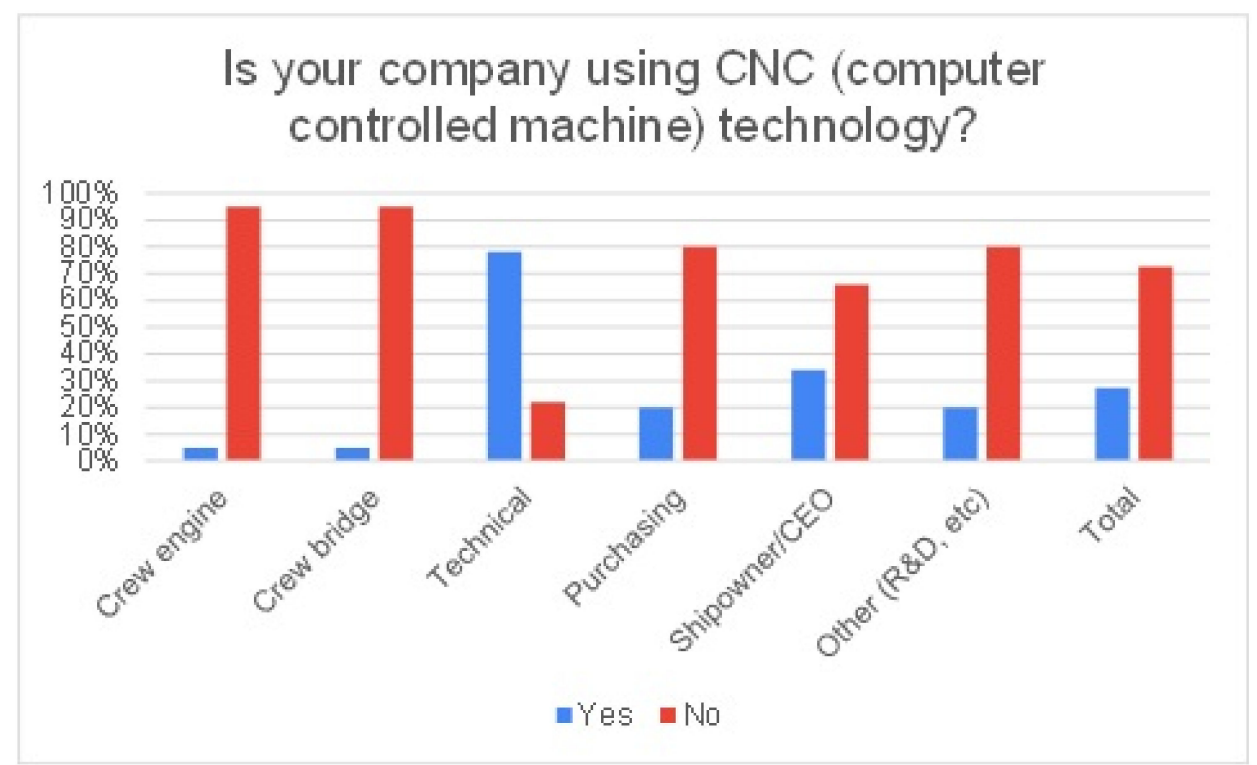

Figure 10. Use of CNC technology.

Spare parts could be made or refurbished on board but only simple and necessary ones. Several participants answered that they preferred to have a stock (Figure 11).

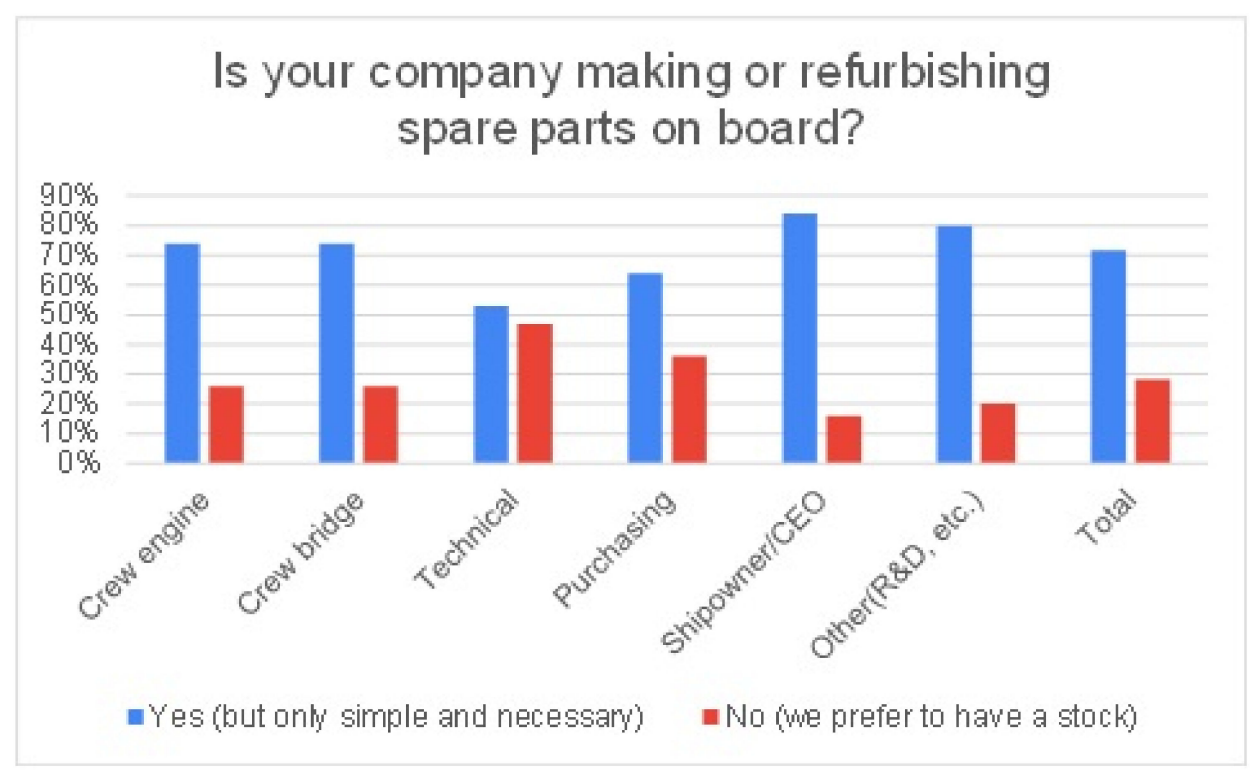

Figure 11. Making or refurbishing spare parts on board.

For making in house (at the company premises or on board) detailed design drawings, the necessary material must be available. However, from the answers, these were not available (Figure 12). 


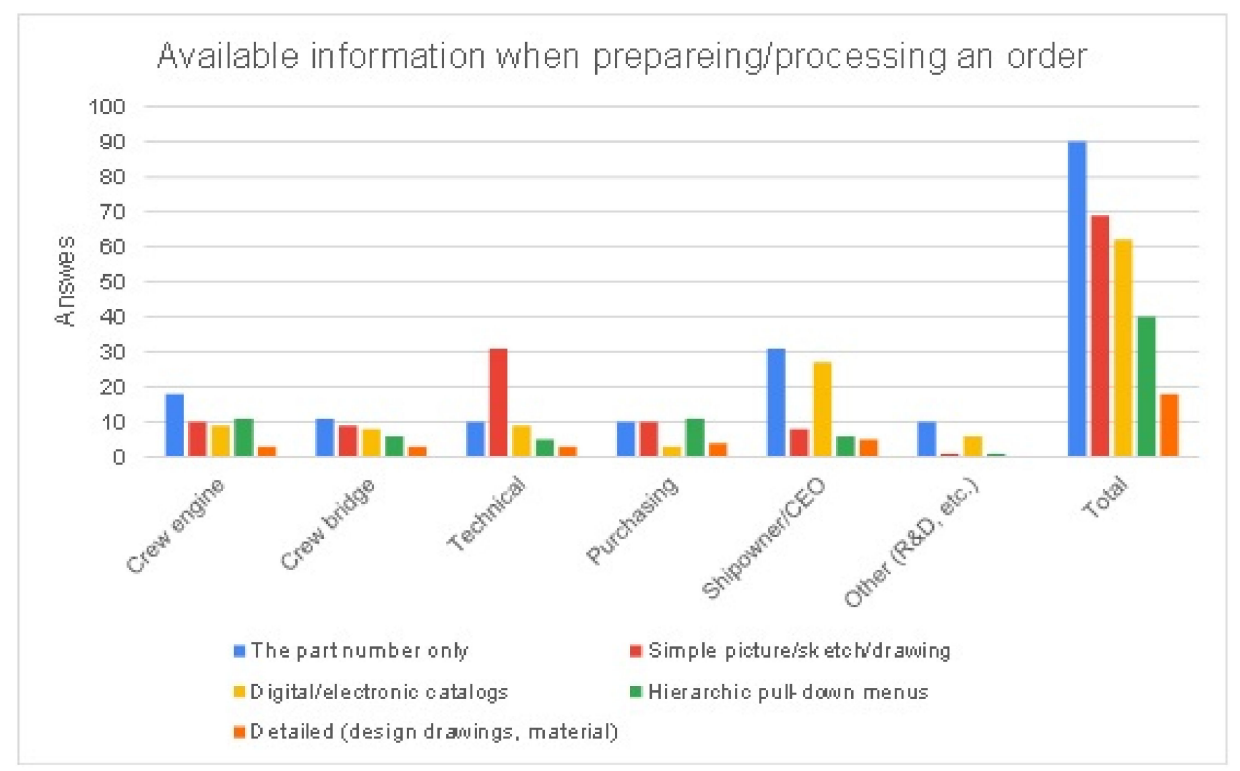

Figure 12. Available information when preparing/processing an order.

\section{Conclusions}

The digitization process of the spare part supply chain with the introduction of AM involves factors that will push it forward and others that are likely to be an obstacle to it. Our research concentrated on the exploration of the end part of the chain in the maritime industry in order to obtain an understanding of the enablers and inhibitors and by capturing the perceptions of the involved end-user stakeholders. The questionnaire method was selected for capturing the views of the selected target group interviewees: people on board a vessel and on the land office: ship owners, seafarers, superintendents and engineers, for example.

The expected benefits from the introduction of 3D printing (cost reductions, improvement of services and storage space reduction) as ranked by the stakeholders at the end of the SPSC (end-users) were found to vary even within a company according to the role. Cost reduction expectations were medium to very high, the improvement of services was medium and storage space reductions were low to medium. The importance of quality came to the surface also from the answer that the majority of the participants would fit a $3 \mathrm{D}$ printed part on the equipment only if it had a quality assurance.

One of the proposed characteristics in the literature for printing spare parts is high value. Due to maritime nature, it makes a low-cost item rise to high value when huge transportation costs to reach the vessels are included. A great percentage of the survey respondents answered that if $3 \mathrm{D}$ printing was applied to low-cost items it would make repairs easier.

End-users have the skills to make or refurbish spare parts on board, could make simple and necessary spare parts and preferred to have a stock. The previous use of CNC technology would make the transition easier but was not found on vessels. The majority of the participants were found to be positive in terms of thinking/examining the use of 3D printing of their companies.

The positive attitudes of shipowners/CEOs were regarded to be more than promising as they are mainly responsible for the acceptance of the companies to adopt new technology.

The most important barrier according to the end-user participants was quality assurance of the spare parts made by the new technology followed by the know-how and staff skills. Moreover, material availability, equipment (the printer) cost, staff skills and material cost were to be shown to be of medium importance. In terms of barriers, quality assurance was by far the most vital barrier as all participants were concerned about how well their parts and the materials that were used for are made. 
As for the parts that are suitable for 3D printing, the participants' choices seemed to follow the characteristics as gathered from the literature, specifically more specific parts that are infrequently demanded, of high value, of small size, that can fit in the process chamber, are of a high supply risk, a small order quantity percentage, items requiring short delivery times and lastly of a high design complexity. Different from the literature was the finding about low-cost items, which received a positive response from participants.

Critical for the successful implementation of AM in the maritime SPSC is to have clearly set goals (that could be overall cost reduction, better service or whatever is predecided). The spare component produced must fit the intended purpose (certification/quality assurance). The overall cost reduction and certification/quality assurance are crucial in order for the venture to gain approval and support at a high level (so the CEO or owner must be convinced first in order to authorize the project and provide the means). Necessary to the decision of the printing is material availability, know-how and skills that should be ensured. Having the aforementioned decisions, approvals and resources, an established project management methodology must be followed for the successful implementation of AM in the SPSC.

The authors have attempted to provide the views of the stakeholders at the end of the chain on board the vessels and at the land office. A similar examination for the supply part of the chain would widen the picture of the SPSC and allow comparisons.

Author Contributions: Conceptualization of the idea, title and layout of the paper, methodology, validation, formal analysis, writing — original draft preparation—review and editing-final manuscript, E.K.; Supervision, direction on the layout and structure of the paper and a review of the draft and final manuscript, N.N.; Review-final manuscript, I.P. All authors have read and agreed to the published version of the manuscript.

Funding: This research received no external funding.

Institutional Review Board Statement: Not applicable.

Informed Consent Statement: Not applicable.

Data Availability Statement: Data are available upon request from the lead author.

Conflicts of Interest: The authors declare no conflict of interest.

\section{References}

1. Eruguz, A.S.; Tan, T.; van Houtum, G.-J. A survey of maintenance and service logistics management: Classification and research agenda from a maritime sector perspective. Comput. Oper. Res. 2017, 85, 184-205. [CrossRef]

2. ISO:ASTM 52900:2015 (en), Additive Manufacturing-General Principles-Terminology. Available online: https://www.iso.org/ obp/ui/\#iso:std:iso-astm:52900:dis:ed-2:v1:en (accessed on 3 January 2021).

3. Standard A.S. Standard Terminology for Additive Manufacturing Technologies. ASTM International F2792-12a. 2012. Available online: https: / /www.astm.org/Standards/F2792.htm (accessed on 19 August 2021).

4. Chekurov, S.; Metsä-Kortelainen, S.; Salmi, M.; Roda, I.; Jussila, A. The perceived value of additively manufactured digital spare parts in industry: An empirical investigation. Int. J. Prod. Econ. 2018, 205, 87-97. [CrossRef]

5. Knofius, N. Towards a Digital Spare Parts Supply Chain. AMQ Services. Available online: https://topsectorlogistiek.nl/wptop/ wp-content/uploads/2020/09/White_paper.pdf (accessed on 19 August 2021).

6. Salmi, M.; Partanen, J.; Tuomi, J.; Chekurov, S.; Björkstrand, R.; Huotilainen, E.; Kukko, K.; Kretzschmar, N.; Akmal, J.; Jalava, K.; et al. Digital Spare Parts; Aalto University; VTT Technical Research Centre: Espoo, Finland, 2018; pp. 3-4.

7. Final Report Pilot Project 3D Printing of Marine Spares. Port of Rotterdam. 2016. Available online: https://www.portofrotterdam. $\mathrm{com}$ /en/ files / final-report-pilot-project-3d-printing-of-marine-spares (accessed on 4 April 2020).

8. Green Ship of the Future. Can 3D Print Technology Be Used for Repair and Reconditioning, Reducing the Number of Scrapped Maritime Parts? Available online: https://greenship.org/can-3d-print-technology-be-used-for-repair-and-reconditioningreducing-the-number-of-scrapped-maritime-parts / (accessed on 16 February 2020).

9. Kandukuri, S. Additive Manufacturing for Marine Parts-A Market Feasibility Study with Singapore Perspective. Available online: https:/ / www.mpa.gov.sg/web/wcm/connect/www/99a3720f-abfc-4b07-9c9b-467220c1000a/Additive+Manufacturing+ Market+Feasibility+Study_Public+Version.pdf?MOD=AJPERES\&id=1572312102868 (accessed on 12 June 2020).

10. Rubino, F.; Nisticò, A.; Tucci, F.; Carlone, P. Marine application of fiber reinforced composites: A review. J. Mar. Sci. Eng. 2020, 8, 26. [CrossRef] 
11. Parmar, H.; Khan, T.; Tucci, F.; Umer, R.; Carlone, P. Advanced robotics and additive manufacturing of composites: Towards a new era in Industry 4.0. Mater. Manuf. Process. 2021, 1-35. [CrossRef]

12. Dalaklis, D.; Katsoulis, G.; Kitada, M.; Schröder-Hinrichs, J.-U.; Ölcer, A.I. A “Net-Centric" conduct of navigation and ship management. Marit. Technol. Res. 2020, 2, 90-107. [CrossRef]

13. Zanoni, S.; Ashourpour, M.; Bacchetti, A.; Zanardini, M.; Perona, M. Supply chain implications of additive manufacturing: A holistic synopsis through a collection of case studies. Int. J. Adv. Manuf. Technol. 2019, 102, 3325-3340. [CrossRef]

14. Mashhadi, R.; Esmaeilian, B.; Behdad, S. Impact of additive manufacturing adoption on future of supply chains. In Proceedings of the International Manufacturing Science and Engineering Conference, Guangzhou, China, 28-29 November 2015; Volume 56826, p. V001T02A064.

15. Khajavi, S.H.; Partanen, J.; Holmström, J. Additive manufacturing in the spare parts supply chain. Comput. Ind. 2014, 65, 50-63. [CrossRef]

16. Liu, P.; Huang, S.H.; Mokasdar, A.; Zhou, H.; Hou, L. The impact of additive manufacturing in the aircraft spare parts supply chain: Supply chain operation reference (scor) model-based analysis. Prod. Plan. Control. 2014, 25, 1169-1181. [CrossRef]

17. Li, Y.; Jia, G.; Cheng, Y.; Hu, Y. Additive manufacturing technology in spare parts supply chain: A comparative study. Int. J. Prod. Res. 2017, 55, 1498-1515. [CrossRef]

18. Ghadge, A.; Karantoni, G.; Chaudhuri, A.; Srinivasan, A. Impact of additive manufacturing on aircraft supply chain performance. J. Manuf. Technol. Manag. 2018, 29, 846-865. [CrossRef]

19. Khajavi, S.H.; Holmström, J.; Partanen, J. Additive manufacturing in the spare parts supply chain: Hub configuration and technology maturity. Rapid Prototyp. J. 2018, 24, 1178-1192. [CrossRef]

20. Westerweel, B.; Basten, R.; den Boer, J.; van Houtum, G.J. Printing spare parts at remote locations: Fulfilling the promise of additive manufacturing. Prod. Oper. Manag. 2021, 30, 161-532. [CrossRef]

21. Delic, M.; Eyers, D.R. The effect of additive manufacturing adoption on supply chain flexibility and performance: An empirical analysis from the automotive industry. Int. J. Prod. Econ. 2020, 228, 107689. [CrossRef]

22. Ratnayake, R.M.C. Making Sense of 3D Printing/Additive Layer Manufacturing in Offshore Petroleum Industry: State of the Art. Ocean Eng. 2016, 7, 2016-54537.

23. Verboeket, V.; Khajavi, S.H.; Krikke, H.; Salmi, M.; Holmstrom, J. Additive Manufacturing for Localized Medical Parts Production: A Case Study. IEEE Access 2021, 9, 25818-25834. [CrossRef]

24. Turrini, L.; Meissner, J. Spare parts inventory management: New evidence from distribution fitting. Eur. J. Oper. Res. 2019, 273, 118-130. [CrossRef]

25. Costantino, F.; di Gravio, G.; Patriarca, R.; Petrella, L. Spare parts management for irregular demand items. Omega 2018, 81, 57-66. [CrossRef]

26. Van der Auweraer, S.; Boute, R.N.; Syntetos, A.A. Forecasting spare part demand with installed base information: A review. Int. J. Forecast. 2019, 35, 181-196. [CrossRef]

27. Zhu, S.; Dekker, R.; van Jaarsveld, W.; Renjie, R.W.; Koning, A.J. An improved method for forecasting spare parts demand using extreme value theory. Eur. J. Oper. Res. 2017, 261, 169-181. [CrossRef]

28. Kostidi, E.; Nikitakos, N. Additive manufacturing of Spare parts in the Maritime Industry in the digital era. In Proceedings of the Annual Conference of the International Association of Maritime Economists (IAME), Athens, Greece, 25-28 June 2019 ; Volume 1.

29. Holmström, J.; Partanen, J.; Tuomi, J.; Walter, M. Rapid manufacturing in the spare parts supply chain: Alternative approaches to capacity deployment. J. Manuf. Technol. Manag. 2010, 21, 687-697. [CrossRef]

30. Vogelsang, K.; Liere-Netheler, K.; Packmohr, S.; Hoppe, U. Barriers to Digital Transformation in Manufacturing: Development of a Research Agenda. In Proceedings of the 52nd Hawaii International Conference on System Sciences, Maui, HI, USA, 8 January 2019; pp. 4937-4946.

31. Osborn, L. 3D Printing and Intellectual Property. In Research Handbook on Digital Transformations; Xavier Olleros, F., Zhegu, M., Eds.; Edward Elgar: Cheltenham, UK, 2016; pp. 254-271. Available online: https://ssrn.com/abstract=2533673 (accessed on 19 August 2021).

32. Kretzschmar, N.; Chekurov, S.; Salmi, M.; Tuomi, J. Evaluating the Readiness Level of Additively Manufactured Digital Spare Parts: An Industrial Perspective. Appl. Sci. 2018, 8, 1837. [CrossRef]

33. Ballardini, R.M.; Ituarte, I.F.; Pei, E. Printing spare parts through additive manufacturing: Legal and digital business challenges. J. Manuf. Technol. Manag. 2018, 29, 958-982. [CrossRef]

34. IEEE. What Are Standards? Why Are They Important? SA Beyond Standards. Available online: https://beyondstandards.ieee. org/general-news/what-are-standards-why-are-they-important/ (accessed on 6 August 2020).

35. ISO:IEC 17065:2012 (en), Conformity Assessment-Requirements for Bodies Certifying Products, Processes and Services. 2012. Available online: https://www.iso.org/obp/ui/\#iso:std:iso-iec:17065:ed-1:v1:en (accessed on 3 June 2020).

36. Lloyd's Register. Available online: https://www.lr.org/th/additive-manufacturing/additive-manufacturing-resources/ guidance-notes-for-the-certification-of-metallic-parts-made-by-additive-manufacturing/ (accessed on 3 May 2020).

37. DNV GL Additive Manufacturing Certification. Available online: https://www.dnvgl.com/services/additive-manufacturingcertification-104684 (accessed on 3 May 2020). 
38. ABS Guidance Notes on Additive Manufacturing. Available online: https://ww2.eagle.org/content/dam/eagle/rules-andguides/current/other/322_guide_for_additive_manufacturing_2021/additive-manufacturing-guide-apr21.pdf (accessed on 17 August 2021).

39. Bureau Veritas Marine and Offshore. Additive Manufacturing-Guidelines for Certification of Product Made Using Wire Arc Additive Manufacturing (WAAM) Process NI662 R00. Available online: https:/ / erules.veristar.com/dy/data/bv/pdf/662-NI_ 2019-05.pdf (accessed on 17 August 2021).

40. Despeisse, M.; Minshall, T. Skills and Education for Additive Manufacturing: A Review of Emerging Issues. In Proceedings of the IFIP International Conference on Advances in Production Management Systems (APMS), Hamburg, Germany, 31 August 2017; pp. 289-297.

41. Gupta, N.; Tiwari, A.; Bukkapatnam, S.T.; Karri, R. Additive Manufacturing Cyber-Physical System: Supply Chain Cybersecurity and Risks. IEEE Access 2020, 8, 47322-47333. [CrossRef]

42. Knofius, N.; Van Der Heijden, M.C.; Zijm, W.H. Selecting parts for additive manufacturing in service logistics. J. Manuf. Technol. Manag. 2016, 27, 915-931. [CrossRef]

43. Lindemann, C.; Reiher, T.; Jahnke, U.; Koch, R. Towards a sustainable and economic selection of part candidates for additive manufacturing. Rapid Prototyp. J. 2015, 21, 216-227. [CrossRef]

44. Yang, S.; Page, T.; Zhang, Y.; Zhao, Y.F. Towards an automated decision support system for the identification of additive manufacturing part candidates. J. Intell. Manuf. 2020, 31, 1917-1933. [CrossRef] 